\title{
Dictionary Name
}

National Cancer Institute

\section{Source}

National Cancer Institute. Dictionary Name. NCI Thesaurus. Code C50399.

A name given to a reference source that lists words and gives their meaning. 